\title{
Vaccination against swine enzootic pneumonia in field conditions: effect on clinical, pathological, zootechnical and economic parameters
}

\author{
Francisco J. PALlarés ${ }^{\mathrm{a}}$,b*, Serafín GómEZ ${ }^{\mathrm{a}}$, Guillermo RAMIS ${ }^{\mathrm{b}}$, \\ Juan SEvA ${ }^{\mathrm{a}}$, Antonio MuÑOZ \\ ${ }^{a}$ U. D. Histología y Anatomía Patológica, Facultad de Veterinaria, Universidad de Murcia, \\ Campus de Espinardo, Aptdo Correos 4021, Murcia 30071, Spain \\ ${ }^{\mathrm{b}}$ Departamento de I + D, CEFUSA, Alhama de Murcia 30840, Murcia, Spain \\ ${ }^{\mathrm{c}}$ Departamento de Producción Animal, Facultad de Veterinaria, Universidad de Murcia, \\ Campus de Espinardo, Murcia 30071, Spain
}

(Received 15 November 1999; accepted 3 July 2000)

\begin{abstract}
A field study was carried out to evaluate the effect of vaccination against swine enzootic pneumonia in different production systems (closed or one-site, and open, two- or three-site, systems). The percentage of mortality showed statistically significant differences $(p<0.001)$ in favour of vaccination in all the production systems examined. Zootechnical and economic parameters also reflected the benefits of vaccination, although only the feed conversion ratio showed statistically significant differences $(p<0.030)$. A macroscopic study of lungs at slaughter pointed to statistically significant differences $(p<0.001)$ in favour of vaccination in the one- and two-site production systems. The histopathological and immunocytochemical study showed complete concordance with the macroscopic diagnosis $(p<0.001)$. Such relationship confirms the suitability of macroscopic diagnosis in field conditions.
\end{abstract}

pig / Mycoplasma hyopneumoniae / enzootic pneumonia / vaccine / field study

Résumé - Vaccination contre la pneumonie enzootique porcine dans les conditions de terrain : effet sur des paramètres cliniques, anatomopathologiques, zootechniques et économiques. Nous avons réalisé une étude dans les conditions de terrain pour évaluer l'effet de la vaccination contre la pneumonie enzootique porcine dans différents systèmes de production (fermé ou un site, et ouverts, deux sites ou trois sites). Le pourcentage de mortalité montre des différences significatives $(p<0,001)$ en faveur des animaux vaccinés quelque soit le système de production. Pour tous les paramètres zootechniques et économiques mesurés, nous avons établi des valeurs favorables chez les animaux

* Correspondence and reprints

Tel.: (34) 968 364704; fax: (34) 968 364147; e-mail: pallares@um.es 
vaccinés, mais seul l'indice de conversion montre une différence significative $(p<0,030)$. Dans les abattoirs, au cours de l'étude macroscopique des poumons, des différences significatives sont apparues $(p<0,001)$ en faveur des animaux vaccinés dans les systèmes de production un site et deux sites. L'étude histopathologique et immunocytochimique a montré une relation statistiquement significative avec le diagnostic macroscopique $(p<0,001)$, ce qui confirme l'efficacité de ce genre de diagnostic dans les conditions de terrain.

porc / Mycoplasma hyopneumoniae / pneumonie enzootique / vaccin / étude de terrain

\section{INTRODUCTION}

Swine enzootic pneumonia (SEP), caused by Mycoplasma hyopneumoniae, is one of the most widespread and costly diseases in intensive pig production systems [9, 16].

The fight against SEP attempts, above all, to prevent the action of other opportunistic agents which may aggravate the process. The principal weapons in this fight are correct handling, medicine-based prevention and immunitary prophylaxis by vaccination.

There have been many tests of the efficacy of vaccination carried out throughout the world, although such tests have normally involved a small number of animals and do not usually take into account the different production systems used in pig rearing.

Any protocol evaluating the efficacy of vaccination against SEP must involve an evaluation of the main clinical parameters, an examination of the lungs at sacrifice in the abattoir, a histopathological and immunocytochemical study of lung samples and an assessment of the principal zootechnical and economic parameters.

In addition to the above, we evaluated the significance which prophylactic protocols may have in different production systems from clinical, pathological, zootechnical and economic points of view. The present study was a practical and realistic test of a vaccine in field conditions in the Mediterranean area.

\section{MATERIALS AND METHODS}

\subsection{Animals and their distribution during the experiment}

A total of 13691 pigs were used in the experiment, of which 7351 were vaccinated against SEP with the commercially available vaccine Stellamune ${ }^{\mathrm{TM}}$ Mycoplasma (Pfizer, S.A., USA), and 6340 were used as controls.

The animals were from the 8 farms of a pig production company in SE Spain, where the climatic conditions, with maximum and minimum average temperatures of $16^{\circ} \mathrm{C} /$ $4{ }^{\circ} \mathrm{C}$ in the winter, $26{ }^{\circ} \mathrm{C} / 15^{\circ} \mathrm{C}$ in the spring, $33{ }^{\circ} \mathrm{C} / 20^{\circ} \mathrm{C}$ in the summer and $22{ }^{\circ} \mathrm{C} / 10^{\circ} \mathrm{C}$ in the autumn, permit the use of natural ventilation systems. Gestation and birth took place on these farms and the animals were finished in 16 fattening units (Tab. I). The vaccinated and control animals within each system were housed separately. Animals born, weaned and fattened on the same farm were said to belong to a closed or "one-site" production system (CS). Those which passed the weaning and transition phase on the farm where they were born before being taken to another site for fattening were said to have been raised in an open "two-site" production system (OS2). When birth/weaning, transition and fattening took place on 3 different sites, the system was designated as an open "three-site" production system (OS3) [5]. All the fattening units of one particular production system 
Table I. Production system and treatment in the fattening units studied.

\begin{tabular}{lcc}
\hline $\begin{array}{l}\text { Fattening } \\
\text { units }\end{array}$ & $\begin{array}{c}\text { Production } \\
\text { system }\end{array}$ & Vaccination \\
\hline 1 & one-site & + \\
2 & one-site & + \\
3 & one-site & + \\
4 & one-site & - \\
5 & one-site & - \\
6 & one-site & - \\
7 & one-site & - \\
8 & two-site & + \\
9 & two-site & + \\
10 & two-site & + \\
11 & two-site & - \\
12 & two-site & - \\
13 & three-site & + \\
14 & three-site & + \\
15 & three-site & + \\
16 & three-site & - \\
\hline
\end{tabular}

were located in the same place and were handled by the same people. The "all in-all out" system was practised in all units. The average pen size was $9 \mathrm{~m}^{2}$, in which 10-12 pigs were housed. The separations between pens allowed nose to nose contact.

On the originating farms, SEP was a subclinical disease which was detected by serology and by the study of the incidence of macroscopic lung lesions in the abattoir. These herds were also seropositive for Aujeszky's disease virus, porcine reproductive and respiratory syndrome virus and Actinobacillus pleuropneumoniae.

\subsection{Prophylactic treatment}

The vaccine was administered in two intramuscular doses of $2 \mathrm{~mL}$ behind the ear or in the internal part of the thigh, as recommended by the vaccine protocol. The first dose was administered during the first week of life and the second after weaning, two weeks later. The control animals did not receive any placebo. Vaccination was carried out in the spring because animals sacrificed at the beginning of autumn were more affected by poor growth and lung lesions than those slaughtered at other times, according to the historical data of the veterinary team of the company.

\subsection{Study of clinical parameters}

The percentage of mortality and causes of death were evaluated. All the units were subjected to the usual clinical and pharmacological treatments considered necessary.

\subsection{Zootechnical and economic parameters}

The parameters studied for the sixteen fattening units were: daily weight gain (DWG), feed conversion ratio (FCR), initial weight, finished weight and medication costs.

\subsection{Macroscopic study of the lesions in the abattoir}

The lungs of fattened pigs were examined in the abattoir, all by the same person, to determine the incidence of macroscopic lesions associated with SEP. These were represented by well defined, greyish-red depressed areas of consolidation, mainly situated in the apical and cardiac lobes, the anterior portion of the diaphragmatic lobes and intermediate lobe $[3,6]$. To score the lesions, a point system was designed from 0 (total absence) to 11 (lungs totally affected), based on the lung surface area affected and with the following distribution: right apical lobe maximum 1 point, left apical lobe maximum 1 point, right cardiac lobe maximum 1 point, left cardiac lobe maximum 1 point, right diaphragmatic lobe maximum 3 points, left diaphragmatic lobe maximum 3 points and intermediate lobe maximum 1 point. 
Table II. Distribution of lung samples destined for histopathological and immunocytochemical study according to production system, treatment and existence or not of macroscopic lesions.

\begin{tabular}{lcrr}
\hline & $\begin{array}{c}\text { Closed production } \\
\text { system }\end{array}$ & $\begin{array}{c}\text { Open production } \\
\text { system }\end{array}$ & Total \\
\hline Vaccinated animals without macroscopic lesions & 2 & 2 & 4 \\
Vaccinated animals with macroscopic lesions & 8 & 10 & 18 \\
Unvaccinated animals without macroscopic lesions & 2 & 5 & 7 \\
Unvaccinated animals with macroscopic lesions & 8 & 10 & 18 \\
Total & 20 & 27 & 47 \\
\hline
\end{tabular}

\subsection{Histopathological and immunocytochemical study}

\subsubsection{Sample taking}

A balanced sample representing all the different fixed factors of the statistical model (production system, prophylactic treatment and presence of macroscopic lesions) was taken based on the results of macroscopic appreciation. In samples with a similar macroscopic lesion score, the possible influence of these effects incorporated in the statistical multifactorial model in the variables (microscopic lesion, complication of microscopic lesion and the score of the immunofluorescence reaction) was measured. Samples were taken from the right apical lobe of the lungs of 47 animals, 22 vaccinated and 25 unvaccinated as the control (Tab. II).

Each sample was divided into two; one was fixed in $10 \%$ formalin and embedded in paraffin and the other frozen in liquid nitrogen for histochemical study.

\subsubsection{Histopathological study}

The histopathological study was carried out using sections obtained from the samples fixed in formalin, paraffin-embedded and stained with hematoxylin-eosin. The microscopic lesions characteristic of SEP corresponded to a model of interstitial pneumonia with an infiltrate of mononuclear cells, pre- dominantly lymphocytes; the alveoli contained macrophagic-like cells and few neutrophil cells; peribronchial, peribronchiolar and perivascular lymphoid clumps of cells of varying degrees of development infiltrated the lamina propria of the bronchioles to a differing extent $[3,8,15]$. To score the microscopic lesions, a point system between 0 and 3 was used according to the following criteria: 0 (absence of microscopic lesions), 1 (slight perivascular, peribronchial and peribronchiolar lymphoid infiltrate), 2 (moderate perivascular, peribronchial and peribronchiolar lymphoid infiltrate) and 3 (abundant perivascular, peribronchial and peribronchiolar lymphoid infiltrate constituting nodulations which press against and compress these structures, thus diminishing their lumen).

In addition, we considered microscopic bronchopneumonic complications caused by secondary agents in each of the samples studied. For statistical purposes, these were scored as follows: 0 (absence of bronchopneumonic complications) and 1 (presence of bronchopneumonic complications).

\subsubsection{Immunocytochemical study}

The immunocytochemical study was carried out by direct immunofluorescence on frozen sections using a polyclonal serum of pig anti-M. hyopneumoniae conjugated with fluorescein isothiocyanate (AFSSA, Ploufragan, France). 
The immunofluorescence reaction at the epithelial level was scored as follows: 0 (no immunofluorescence reaction), 1 (slight immunofluorescence reaction), 2 (medium level of immunofluorescence reaction) and 3 (strong immunofluorescence reaction).

\subsection{Statistical analysis}

Least squares analysis of means was used in the statistical study of clinical parameters, macroscopic lesions in the abattoir and zootechnical and economic parameters

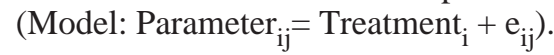

A variety of statistical models of varying degrees of complexity from a simple least squares analysis of means to a multifactorial model incorporating all the effects (production system, prophylactic treatment and presence of macroscopic lesions), was used in the histopathological and immunocytochemical study in order to clarify the possible influence of the different variables (microscopic lesion, complication of microscopic lesion and the score given to the immunofluorescence reaction).

The statistical analyses used were:

- 9 least squares analyses of means (Model: Variable $_{\mathrm{ij}}=$ Effect $_{\mathrm{i}}+\mathrm{e}_{\mathrm{ij}}$ );
- 9 multifactorial analyses with 2 factors (Model: Variable $_{i j k}=\operatorname{Effect}(1)_{i}+$ $\left.\operatorname{Effect}(2)_{\mathrm{j}}+(\operatorname{Effect}(1) \times \operatorname{Effect}(2))_{\mathrm{ij}}+\mathrm{e}_{\mathrm{ijk}}\right)$;

- 3 multifactorial analyses with 3 factors

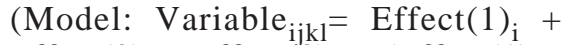
$\operatorname{Effect}(2)_{\mathrm{j}}+\operatorname{Effect}(3)_{\mathrm{k}}+(\operatorname{Effect}(1) \times$ $\operatorname{Effect}(2))_{\mathrm{ij}}+(\operatorname{Effect}(1) \times \operatorname{Effect}(3))_{\mathrm{ik}}+$ $(\operatorname{Effect}(2) \times \operatorname{Effect}(3))_{\mathrm{jk}}+(\operatorname{Effect}(1) \times$ $\left.\operatorname{Effect}(2) \times \operatorname{Effect}(3))_{\mathrm{ijk}}+\mathrm{e}_{\mathrm{ijkl}}\right)$;

- 2 multifactorial analyses with 3 factors and one covariable (Model: Variable $_{i \mathrm{jkl}}=$ $\operatorname{Effect}(1)_{\mathrm{i}}+\operatorname{Effect}(2)_{\mathrm{j}}+\operatorname{Effect}(3)_{\mathrm{k}}+$ $(\operatorname{Effect}(1) \times \operatorname{Effect}(2))_{\mathrm{ij}}+(\operatorname{Effect}(1) \times$ $\operatorname{Effect}(3))_{\mathrm{ik}}+(\operatorname{Effect}(2) \times \operatorname{Effect}(3))_{\mathrm{jk}}+$ $(\operatorname{Effect}(1) \times \operatorname{Effect}(2) \times \operatorname{Effect}(3))_{\mathrm{ijk}}+$ Covariable $\left.+\mathrm{e}_{\mathrm{ijkl}}\right)$.

The Systat 5.1 ${ }^{\mathrm{TM}}$ program for Windows was used for the above analyses [17].

\section{RESULTS}

\subsection{Clinical parameters}

There were significant differences $(p<0.001)$ in the percentage of mortality between the vaccinated and unvaccinated animals in all of the production systems, the difference in favour of the former being $1.39 \%$ in CS, $2.86 \%$ in OS2 and $2.38 \%$ in

Table III. Percentage of mortality and causes of death.

\begin{tabular}{|c|c|c|c|c|c|c|}
\hline \multirow[t]{2}{*}{ Cause of death } & \multicolumn{2}{|c|}{ Closed system } & \multicolumn{2}{|c|}{$\begin{array}{l}\text { Open "two-site" } \\
\text { system }\end{array}$} & \multicolumn{2}{|c|}{$\begin{array}{c}\text { Open "three-site" } \\
\text { system }\end{array}$} \\
\hline & Vaccinated & Control & Vaccinated & Control & Vaccinated & Control \\
\hline Pneumonia & 0.47 & 0.75 & 0.05 & 0.18 & 0.22 & 0.20 \\
\hline Gastric ulcer & 0.35 & 0.98 & 0.56 & 0.80 & 0.45 & 1.00 \\
\hline Diarrhoea & 0 & 0 & 0 & 0.36 & 0 & 0 \\
\hline Enterotoxemia & 0 & 0 & 0.19 & 1.40 & 0.13 & 0 \\
\hline Encephalitis & 0 & 0 & 0 & 0.27 & 0 & 0 \\
\hline Stress & 0.06 & 0 & 0.23 & 0.09 & 0.31 & 0.90 \\
\hline Weakness & 0.39 & 0.93 & 0 & 0.62 & 0 & 0.70 \\
\hline Other causes & 0 & 0 & 0.14 & 0.09 & 0.09 & 0.20 \\
\hline Undiagnosed & 0 & 0 & 0.23 & 0.45 & 0.22 & 0.80 \\
\hline Total $\%$ losses & 1.27 & 2.66 & 1.40 & 4.26 & 1.42 & 3.80 \\
\hline
\end{tabular}


Table IV. Least square analysis of means for the principal zootechnical and economic parameters.

\begin{tabular}{lccc}
\hline Parameters & \multicolumn{2}{c}{ Least squares analysis of means } & \multirow{2}{*}{$\begin{array}{c}p \\
\text { (level of } \\
\text { significance) }\end{array}$} \\
\cline { 2 - 3 } & Control & Vaccinated & NS \\
\hline Daily weight gain & 0.751 & 0.764 & 0.030 \\
Feed conversion ratio & 2.537 & 2.454 & NS \\
Initial weight $(\mathrm{kg})$ & 19.554 & 19.319 & NS \\
Finished weight $(\mathrm{kg})$ & 103.674 & 106.411 & NS \\
Medication costs (pesetas) & $341.79(2.05 €)$ & $323.77(1.95 €)$ & \\
\hline
\end{tabular}

OS3. The differences between production systems were not significant.

Table III shows the percentages of loss through mortality and the causes of death in the different production systems. The main causes of mortality in the fattening period were gastric ulcer and wasting. In the case of loss through pneumonia, in which $M$. hyopneumoniae probably acted as the principal agent, significant differences $(p<0.001)$ between vaccinated and control animals were only found in OS2, although the percentage of mortality from this cause was very small.

\subsection{Zootechnical and economic parameters}

DWG showed an increase of 13 grams in vaccinated animals although the difference was not significant. In FCR there was a diminution of $0.083(p<0.030)$ in favour of the vaccinated animals. The initial and finished weights showed no significant differences between vaccinated and control animals, although the former weighed an average $2.737 \mathrm{~kg}$ more. In medication costs, there was a diminution of 18.02 pesetas $(0.10 €)$ in favour of the vaccinated animals although this did not represent significant differences (Tab. IV).

\subsection{Incidence of pulmonary lesions in the abattoir}

Data from 6188 lungs were obtained by macroscopic examination at the abattoir. The only lesions scored were those compatible with SEP. Table V shows the mean scores given to macroscopic lung lesions at sacrifice in vaccinated and control animals for each production system. It was not possible to ascertain differences in OS3 due to unforeseen changes in the time at which the control animals were sacrificed.

Table V. Mean scores for lung lesions at sacrifice.

\begin{tabular}{|c|c|c|c|c|c|c|c|c|}
\hline \multirow[t]{2}{*}{ Production systems } & \multicolumn{3}{|c|}{ Vaccinated } & \multicolumn{3}{|c|}{ Unvaccinated } & \multirow{2}{*}{$\begin{array}{c}\text { Level of } \\
\text { significance }\end{array}$} & \multirow{2}{*}{$\underset{\%}{\text { Reduction }}$} \\
\hline & LSM & SE & $n$ & LSM & SE & $n$ & & \\
\hline Clos & 314 & 0.0 & 21 & 5 & $0 .($ & 947 & $p<0.001$ & 14.6 \\
\hline Open "two-site" system & 1.624 & 0.054 & 1298 & 2.659 & 0.202 & 91 & $p<0.001$ & 38.92 \\
\hline Open "three-site" system & 1.722 & 0.13 & 1750 & $-(1)$ & - & - & - & - \\
\hline
\end{tabular}

LSM: Least squares analysis of means. SE: Standard error. $n$ : Size of population.

(1) No data available for this group. 
Table VI. Scoring of microscopic lesions and bronchopneumonic complications in CS and OS samples.

\begin{tabular}{lccccccc}
\hline & \multicolumn{2}{l}{ Animals with macroscopic lesion } & & \multicolumn{2}{c}{ Animals without macroscopic lesion } \\
\cline { 2 - 3 } \cline { 7 - 8 } & $\begin{array}{c}\text { Nb. of } \\
\text { samples }\end{array}$ & Score & $\begin{array}{c}\text { Nb. of } \\
\text { complications }\end{array}$ & & $\begin{array}{c}\text { Nb. of } \\
\text { samples }\end{array}$ & Score & $\begin{array}{c}\text { Nb. of } \\
\text { complications }\end{array}$ \\
\hline Vaccinated CS & 8 & 1.7 & $4(8)$ & & 2 & 1 & $0(2)$ \\
Controls CS & 8 & 1.7 & $5(8)$ & & 2 & 0.75 & $0(2)$ \\
Vaccinated OS & 10 & 2.55 & $3(10)$ & & 2 & 2 & $0(2)$ \\
Controls OS & 10 & 2.35 & $9(10)$ & & 5 & 1.4 & $0(5)$ \\
\hline
\end{tabular}

Statistical analysis of the mean scores for the lung lesions pointed to significant differences between the vaccinated and control animals in CS (1.314 versus 1.539) and in OS2 (1.624 versus 2.659), at the highest degree of significance $(p<0.001)$.

\subsection{Histopathological and immunocytochemical study}

\subsubsection{Histopathological study (Tab. VI)}

The data obtained showed that a similar incidence of macroscopic lesions in both vaccinated and control animals from CS gave a similar mean score of 1.7. The number of complications in the same samples was also very similar. In samples from vaccinated animals which showed no macroscopic lesions the mean score was 1 , whereas in samples from control animals without macroscopic lesions the mean score was 0.75 . Complications by opportunistic agents were 0 in both vaccinated and control animals. In OS animals, with a similar incidence of macroscopic lesions in both vaccinated and control animals, the mean score was nearly the same in the vaccinated and control animals. Complications by opportunistic agents were fewer in the vaccinated than in the control animals. For samples from vaccinated animals with no macroscopic lesions the mean score was 2 , whereas in samples from control animals without macroscopic lesions the mean score was 1.4. Complications by opportunistic agents were 0 in both vaccinated and control animals.

\subsubsection{Immunocytochemical study}

\subsubsection{Positive reaction towards M. hyopneumoniae}

Of the vaccinated animals raised in CS conditions, $40 \%$ tested positive as opposed to $60 \%$ of the control group. The corresponding figures for OS animals were $66.66 \%$ and $53.33 \%$. When the production system was not taken into account, $54.54 \%$ of the vaccinated and $56 \%$ of the controls were positive. All the lung samples which showed no evident sign of macroscopic lesions tested negative to immunofluorescence. These results did not point to statistically significant differences.

\subsubsection{Scoring the immunofluorescence reaction}

The score reflected the concentration of mycoplasmas in each sample according to the intensity of the immunocytochemical reaction.

Of the animals reared in CS, the mean scores of vaccinated animals and controls were 0.8 and 1.1, respectively. In OS reared animals, the corresponding scores were 1.54 for vaccinated animals and 1.27 for the controls. In the samples which showed no macroscopic lesions, the score was always 0 . 
Table VII. Levels of significance obtained in the different statistical models used in the histopathological and immunocytochemical study.

\begin{tabular}{|c|c|c|c|c|c|c|c|c|c|c|c|c|}
\hline & \multicolumn{3}{|c|}{$\begin{array}{l}\text { Least squares } \\
\text { analyses of means }\end{array}$} & \multicolumn{3}{|c|}{$\begin{array}{l}\text { Multifactorial analyses } \\
\text { with } 2 \text { factors* }\end{array}$} & \multicolumn{3}{|c|}{$\begin{array}{l}\text { Multifactorial analyses } \\
\text { with } 3 \text { factors * }\end{array}$} & \multicolumn{3}{|c|}{$\begin{array}{c}\text { Multifactorial analyses } \\
\text { with } 3 \text { factors and } \\
1 \text { covariable } \\
\text { (microscopic lesion) * }\end{array}$} \\
\hline & PS & TR & ML & PS & TR & ML & PS & TR & ML & PS & TR & ML \\
\hline $\begin{array}{l}\text { Variables } \\
\text { Microscopic } \\
\text { lesion }\end{array}$ & $p=0.003$ & NS & $p<0.001$ & $p<0.001$ & NS & $p<0.001$ & $p<0.001$ & $1 \mathrm{NS}$ & $p<0.001$ & $1-$ & - & - \\
\hline Complication & NS & NS & $p<0.001$ & NS & NS & $p<0.001$ & NS & NS & $p<0.001$ & $1 \mathrm{NS}$ & NS & $p=0.013$ \\
\hline $\begin{array}{l}\text { Immuno- } \\
\text { fluorescence } \\
\text { reaction }\end{array}$ & NS & NS & $p<0.001$ & NS & NS & $p<0.001$ & NS & NS & $p<0.001$ & $1 \mathrm{NS}$ & NS & $p=0.013$ \\
\hline
\end{tabular}

PS: Production system. TR: Prophylactic treatment. ML: Presence of macroscopic lesions.

* The interactions between the effects studied in the different multifactorial analyses showed no statistically significant differences.

These results did not point to statistically significant differences.

\subsubsection{Statistical analysis}

The battery of statistical analyses carried out showed that only the macroscopic diagnosis was significantly related to the histopathological and immunocytochemical studies made (Tab. VII). Neither the production system nor prophylactic treatment represented a statistically significant effect.

\section{DISCUSSION}

There is a high pig density in SE Spain, where the climate permits natural ventilation systems to be used and renders heating systems unnecessary. Such characteristics mean that a trial of any vaccination against SEP may show differences from other trials conducted in central or northern Europe, where artificial ventilation and heating systems are necessary.

Besides the above differences, the study described here is based on a much larger number of pigs (13691) than that used in other experiments $[1,2,10-12]$. The study, which was carried out in a pig-rearing company, also takes into account the different systems which are used in the field.

The percentage of mortality during fattening showed a statistically significant difference in favour of vaccinated animals, a result which was not obtained in other field studies using the same vaccine $[10,11]$.

All the zootechnical and economic parameters pointed to the advantage of vaccination, although only FCR showed a statistically significant difference between control and vaccinated animals. The FCR of 2.537 of control animals diminished by 0.083 in vaccinated animals, which was less than the 0.1 obtained by Martinod [12] and the 0.27 obtained by Blagović [2], although in both cases the authors started with an FCR of above 3 so that the greater decreases are not that surprising. Whatever the case, the significant improvement in this parameter is of great importance because of its biological and economic importance.

The scoring system for studying lung lesions in the abattoir differs from other 
systems based on the area of the lung that is affected $[4,13]$ and can be used in a situation where up to 360 animals per hour are sacrificed. The study points to statistically significant lower scores in favour of vaccinated animals in CS and OS2, although such a reduction in open production systems could not be confirmed by the results from OS3, since the control animals of this group were unexpectedly slaughtered before our veterinary team arrived at the abattoir. However, as in the percentage of mortality, there seemed to be a tendency for improved results in open systems since, as Harris [5] affirms, physically separating the production phases interrupts the propagation cycle of many pathogens, therefore improving sanitary conditions. Other field studies have pointed to a greater diminution of scores with the same vaccine both in CS [7, 12] and OS2 [1, 2]. The extent of any diminution in the number of lesions observed at slaughter will depend on the degree of SEP infection existing in a particular farm at the time of vaccination. It must be remembered that in our case the originating farms were seen to be SEP positive by serology and according to tests at the abattoir, the disease existed subclinically at the farms.

The scoring system used in the histopathological study differed from that described by Livingston [8], which was designed for experimental models and which, apart from measuring the number of lymphoid nodules and their penetration in the submucosa, measures the quantity of cells in the alveoli and bronchi. Because the presence of neutrophils is more evident in the initial stages of the disease [8] and because the polymorphonuclear response diminishes and lymphoid hyperplasia intensifies as the process becomes chronic [14] (as in the case of animals in the abattoir), we classified the presence of neutrophils as secondary agent complications. The score referring to the intensity of the immunofluorescent reaction was intended to reflect the concentration of mycoplasma in the respiratory epithelium in animals at slaughter.
Representative sampling according to the macroscopic diagnosis, production system and vaccination for the histopathological and immunocytochemical study establishes any variations between groups in the scoring of the microscopic lesions, the number of complications in the microscopic lesions and the immunofluorescent reaction. The increasingly complex battery of statistical analyses used permitted a series of combinations of the variables (microscopic lesions, the number of complications in the microscopic lesions and immunofluorescent reaction) and effects (production system, prophylactic treatment and degree of macroscopic lesions) to be assessed and to see the relative importance of each. Such analyses showed that the lesions diagnosed macroscopically in the abattoir were confirmed by the results obtained in the histopathological and immunocytochemical study. This led us to affirm that the degree of macroscopic lesions is an effective estimate of the pathological effect of SEP and a useful diagnostic tool, sometimes the only one available, for a large number of animals in field conditions when time is short, as occurs in a conventional sacrifice line in an abattoir.

The clinical, pathological, zootechnical and economic results obtained by the above means in the field experiment described confirm the efficacy of vaccination in the fight against such a widespread disease as SEP in intensive pig-rearing units.

\section{REFERENCES}

[1] Bilić V., Lipej Z., Valpotic I., Habrun B., Humski A., Njari B., Mycoplasmal pneumonia in pigs in Croatia: first evaluation of a vaccine in fattening pigs, Acta Vet. Hung. 44 (1996) 287-293.

[2] Blagović S., Fluksek V., Lausin M., Stiglic N., Cazin P., Clinical evaluation of the protective capabilities of an adjuvanted Mycoplasma hyopneumoniae vaccine, Proceedings of the 12th International Pig Veterinary Society Congress, The Hague, 1992, p. 327.

[3] Doster A.R., Lin B.C., Identification of Mycoplasma hyopneumoniae in formalin-fixed 
porcine lung, using an indirect immunoperoxidase method, Am. J. Vet. Res. 49 (1988) 1719-1721.

[4] Hannan P.C.T., Bhogal B.S., Fish J.P., Tylosin tartrate and tiamutilin on experimental piglet pneumonia induced with pneumonic pig lung homogenate containing mycoplasmas, bacteria and viruses, Res. Vet. Sci. 33 (1982) 76-88.

[5] Harris D.L., Alternative approaches to eliminate endemic diseases and improving performances of pigs, Vet. Rec. 123 (1988) 422-423.

[6] Kobisch M., Blanchard B., Le Potier M.F., Mycoplasma hyopneumoniae infection in pigs: duration of the disease and resistance to reinfection, Vet. Res. 24 (1993) 67-77.

[7] Le Grand A., Kobisch M., Comparaison de l'utilisation d'un vaccin et d'un traitement antibiotique séquentiel dans un élevage infecté par $\mathrm{Myco-}$ plasma hyopneumoniae, Vet. Res. 27 (1996) 241-253.

[8] Livingston C.W., Stair E.L., Underdahl N.R., Mebus C.A., Pathogenesis of mycoplasmal pneumonia in swine, Am. J. Vet. Res. 33 (1972) 22492258.

[9] Madec F., Fourichon C., Morvan P., Labbé A., Économie et santé en production porcine, INRA Prod. Anim. 5 (1992) 149-161.

[10] Maes D., Deluyker H., Verdonck M., Castryck F., Miry C., Lein A., Vrijens B., de Kruif A., The effect of vaccination against Mycoplasma hyopneumoniae in pigs herds with a continuous production system, Zentralbl. Veterinaermed. B 45 (1998) 495-505
[11] Maes D., Deluyker H., Verdonck M., Castryck F., Miry C., Vrijens B., Verbeke W., Viaene J., de Kruif A., Effect of vaccination against Mycoplasma hyopneumoniae in pigs herds with an all-in/all-out production system, Vaccine 17 (1999) 1024-1034.

[12] Martinod S., Protection against Mycoplasma hyopneumoniae and Actinobacillus pleuropneumoniae infections using a mycoplasma inactivated vaccine Respisure ${ }^{\circledR}$ under field conditions, Proceedings of the 14th International Pig Veterinary Society Congress, Bologna, 1996, p. 221.

[13] Morris C.R., Gardner I.A., Hietala S.K., Carpenter T.E., Enzootic pneumonia: comparison of cough and lung lesions as predictors of weight gain in swine, Can. J. Vet. Res. 59 (1995) 197-204.

[14] Ross R.F., Mycoplasmal Diseases. in: Straw B.E., D'Allaire S., Mengeling W.L., Taylor D.J. (Eds.), Diseases of swine, 8th ed., Iowa State University Press, Ames, Iowa, USA, 1999, pp. 495-510.

[15] Sørensen V., Ahrens P., Barfod K., Feenstra A.A., Feld N.C., Friis N.F., Bille-Hansen V., Jensen N.E., Pedersen M.W., Mycoplasma hyopneumoniae infections in pigs: Duration of the disease and evaluation of four diagnostic assays, Vet. Microbiol. 54 (1997) 23-34.

[16] Straw B.E., Tuovinen V.K., Bigras-Poulin M., Estimation of the cost of pneumonia in swine herds, J. Am. Vet. Med. Assoc. 195 (1989) 17021706.

[17] SYSTAT for Windows: Statistics, Version 5 Edition Evanston, IL: SYSTAC, Inc, 1992, 750 p. 